\title{
28 Research Guare \\ Porin Protein Could be A Vaccine Candidate Against Riemerella Anatipestifer for Ducks
}

\author{
Hui Yang \\ Hainan University \\ Haiwen Zhang \\ Hainan University \\ Chenghong Liao \\ Hainan University \\ Jianguo Zhao \\ Hainan University \\ Jinhua Wang \\ Hainan University \\ Kebang Wu \\ Hainan University \\ Qian Han \\ Hainan University \\ qingfeng guan ( 249430978@qq.com ) \\ Hainan University https://orcid.org/0000-0003-0567-2650
}

\section{Original article}

Keywords: RA, subunit vaccine, bioinformatics analysis

Posted Date: August 19th, 2020

DOI: https://doi.org/10.21203/rs.3.rs-58801/v1

License: (c) (1) This work is licensed under a Creative Commons Attribution 4.0 International License.

Read Full License 


\section{Abstract}

Riemerella anatipestifer(RA) is a gram-negative bacterium that is susceptible to poultry such as domestic ducks and geese. Young birds have a high mortality rate after infection. The resistance caused by the abuse of antibiotics is also getting worse. Since there are 25 serotypes of $R A$, and the cross-immunization between serotypes is weak, it is necessary to find a vaccine that has cross-immunization against multiple serotypes of $R A$. In this article, the bioinformatics analysis of $R A$ Proin protein was conducted, and it was speculated that it has the potential of a subunit vaccine. The protein was recombinantly expressed and purified, and immunized with Cherry Valley Duck. The results show that the serum antibodies of the Porin protein immunized group were positive at 1:24300 for the porin protein and $R A$ strains $\mathrm{CH} 1$. The serum could improve the killing effect of complement and phagocytic cells on RA. After the challenge, the survival rate of Cherry Valley Duck can be increased by $80 \%$.

\section{Key Points:}

- There are 21 serotypes of $R A$, but the cross immunoprotective effect between each serotype is extremely weak. The development of subunit vaccines is a powerful way to prevent the infection of multiple serotypes of $R A$.

- Through bioinformatics analysis, it was found that Porin protein is conserved in $R A$ and also has abundant epitopes. It is speculated that this protein has the potential to develop a subunit vaccine.

- The recombinant Porin protein was used to immunize Cherry Valley Duck. The serum produced had a cross-immunization effect on serum type 1 and serum type $3 R A$, and enhanced the clearance of pathogens by complement and phagocytes. After challenge, the survival rate of Cherry Valley was improved.

\section{Introduction}

RA is a contact infectious bacterium that infects domestic ducks, geese(Chen, Lee, Chou, \& Tsai; ShuChuan, Wen-Hua, Yung-Fu, \& Chao-Fu, 1999), turkeys(Rubbenstroth, Ryll, Behr, \& Rautenschlein) and a variety of birds(Hinz, Ryll, \& Köhler, 1998). Its infection symptoms are fibrinous pericarditis, fibrinous perihepatitis, fibrinous air sacs, encephalitis, Arthritis, etc. The disease was first reported in Long Island, New York, USA in 1932, and subsequently in Europe, South Asia, and Oceania. At present, the occurrence and prevalence of this disease is extremely extensive, and the disease is prevalent in almost all places where ducks are raised. All kinds of ducks in poultry can be infected. Under natural conditions, ducks of all ages are susceptible, and the incidence rate is about $90 \%(Z h u, C h e n, \& L i, 2017)$.

Drug treatment is one of the important measures to prevent and treat the disease, mainly antibiotics and horizontal amines. The disease can occur in the whole stage of duck breeding, and birds can be infected repeatedly, resulting in higher cost of medication. Clinically, drug abuse, poor therapeutic effects, and even treatment failures often occur. Although $R A$ is sensitive to many antibiotics, it is highly susceptible to drug resistance(Sun, Zhu, Xu, Jia, \& Cheng, 2019; Xing et al., 2015). Different regions have different 
susceptibility to antibacterial drugs in different regions, which brings difficulties to the actual treatment work. Therefore, immunization is an effective way to prevent and control this disease. The vaccines currently used to prevent this disease mainly include inactivated vaccines, attenuated vaccines, and subunit vaccines. Due to the complexity of $R A$ serotypes and the lack of cross-protection between different serotypes, both attenuated and inactivated vaccines are effective against specific serotypes but are not protective against other serotypes of $R A$.

Gram-negative outer membrane proteins (Omps) not only play an important role in maintaining the integrity of the cell envelope and transmembrane transport of the substances, but also in the the adhesion of bacteria to invading cells and bacteria to serum resistance. Outer membrane proteins can be divided into major proteins and microproteins according to their copy number in cells. Among them, Porin protein, also known as channel-forming protein, has a transmembrane domain with only 10 to 12 amino acid residues, forming a $\beta$-sheet structure, and antiparallel $\beta$-sheets interact to form a non-specific transmembrane. The channel allows small molecules with a relative molecular mass of less than 10,000 $D$ to pass freely and is associated with bacterial resistance. Studies have shown that porin protein has good immunoprotective effects against strains such as E. coli(Fox, Thomson, Drouillard, Thornton, \& Nagaraja, 2009), Salmonella(Dodd, Renter, Thomson, \& Nagaraja, 2011) and Pseudomonas aeruginosa(Bahey-El-Din, Mohamed, Sheweita, Haroun, \& Zaghloul, 2020). According to the genome sequencing results of $R A$ (Wang, et al., 2012), it was found that porin was also present in $R A$. At present, the research of $R A$ porin is still in the prediction stage, and there are no reports of expression and immune protection analysis.

In this paper, the conservation, structural properties and immunogenicity of porin protein were analyzed by bioinformatics, and the duck was immunized by recombinant expression of the protein to verify the cross-immunoprotective effect and immune mechanism of the protein.

\section{Material And Methods}

\section{Bacterial strains and culture conditions}

$R A$ strain ATCC 11845 were purchased from Shanghai yiyan biological technology Co. Ltd (ShangHai, China). Serotype $1 R A$ strain $\mathrm{CH}-1$ (RA-CH1) was isolated from sick ducks in HaiKou, China. $R A$ strains were grown in tryptic soy broth medium (TSB) and at $37^{\circ} \mathrm{C}$. E. coli strain DH5a and BL21 (DE3) strains were purchased from TransGen Biotech, Inc. (Beijing, China). E. coli strains were grown on Luria-Bertani (LB) agar.

\section{Animals}

30 One-day-old Cherry Valley ducklings obtained from the Hainan Tianyuan Industrial Co., Ltd.(Haikou, China). The ducks were housed in cages, and provided water and food adlibitum during the study. The animal experiments were conducted in strict accordance with the recommendations in the Guide for the 
Care and Use of Laboratory Animals of the Institutional Animal Care and Use Committee guidelines set by HanNan University.

\section{Signal peptide prediction}

Signal peptide cleavage site was predicted by SignalP 5.0 (http://www.cbs.dtu.dk/services/SignalP/).

\section{Homology analysis and phylogenetic tree construction}

The RA Porin protein (Uniprot NO. E4TDA8) was blasted by UniProtKB database with parameters including E-Threshold 10, Matrix BLOSUM-62 and no filtering in Uniprot (https://www.uniprot.org/blast/). The number of returned alignments was 50 . The blasted data was aligned with ClustalW and phylogeny tree was constructed by MEGAX.

\section{Transmembrane structure prediction}

Mature peptide sequence of $R A$ Porin protein was pasted into PRED-TMBB web server (http://biophysics.biol.uoa.gr/PRED-TMBB/input.jsp)(Bagos, Liakopoulos, Spyropoulos, \& Hamodrakas, 2004), which is for predicting the topology of beta-barrel outer membrane proteins. Viterbi (VI), N-best (NB) and Posterior Decoding (DY) method were applied and the common part of the three analyses was as prediction results.

\section{Tertiary structure prediction}

The tertiary structure of the Porin protein sequence from which the signal peptide was removed was predicted by the swissmodel online server (https://swissmodel.expasy.org/).

\section{Antigenic prediction}

The B cell epitopes were predicted by ElliPro web server (http://tools.iedb.org/ellipro/) based based upon structural protrusion. The predicted results were screened to retain only epitopes outside the membrane.

\section{Expression and purification of poring protein of $R A$}

The $R A$ genome is extracted by the genome extraction kit (TIANGEN Biotech(Beijing)Co.,Ltd.,BeiJing, China), and the porin gene is amplified by primer pairs porin F: 5'-GGATCCGTACCAGATACTATTATCGTTC3' and porin R: 5'-GCGGCCGCAATTCCTATTTCTACTTGAAATCT-3', with Restriction site BamH 1 and Not1. The gene was then ligated into the $\mathrm{PET} 28 \mathrm{a}$ vector, and the recombined vectors were transformed into BL21 competent cells. These successfully transformed BL21 E. coli cells were induced to express the target protein by auto-inducing medium(Studier, 2014). The expressed product was subjected to cleavage, separation, denaturation, renaturation, dialysis, and finally purification through a nickel column based on the previous protocol(Saleem, Moore, \& Derrick, 2012). All proteins were determined by $12 \%$ sodium dodecyl sulfatepolyacrylamide gel electrophoresis (SDS-PAGE). The protein was then lyophilized with the ALPHA 1-2 LD plus freeze dryer (Christ, Germany) and kept in $-20^{\circ} \mathrm{C}$. 


\section{Immunization protocols}

The Cherry Valley ducks were randomly divided into 3 groups of 10 animals each injected with PBS (PBS group), PBS + adjuvant (PBS + adjuvant group), PBS + adjuvant + Porin protein (Porin group). The ducks were first immunized at 7 days of age. The Porin protein was mixed with Freund's complete adjuvant in a 1:1 oily form and injected subcutaneously. For the second immunization 7 day post the first immunization, Porin protein was mixed with Freund's incomplete adjuvant by 1:1 to form an oil emulsion. Both immunization doses were $0.2 \mathrm{mg} /$ duck. The days of blood collection was 1, 7, 14, 21 and 28 days post the first immunization.

\section{Indirect enzyme-linked immunosorbent assay (iELISA) for Porin protein and $R A$ cells detection}

96-well plates were coated at a concentration of $2 \mu \mathrm{g} / \mathrm{ml}$ protein antigen with $100 \mu \mathrm{l} /$ well, overnight at $4^{\circ}$ $\mathrm{C}$, and washed 4 times with $100 \mu \mathrm{l}$ PBST wash for 5 min each. The plates were added with $200 \mu \mathrm{l} /$ well blocking solution and incubaed at $37^{\circ} \mathrm{C}$ for 2 hours. Then the plates were washed 4 times with each time $5 \mathrm{~min}$. The first well was diluted 1:100, diluted 1:3 in a gradient, $100 \mu \mathrm{l} /$ well. The plates were then incubated at $37^{\circ} \mathrm{C}$ for $1.5 \mathrm{~h}$, and washed 4 times for 5 min each time. Horseradish-labeled mouse antiduck IgG (baiaolaibo, Beijing) was diluted 1:5000, $100 \mu \mathrm{l} /$ well, incubated at $37^{\circ} \mathrm{C}$ for 20 to $30 \mathrm{~min}$, and washed 4 times for 5 min each time. The plates were added with $1 \times \mathrm{TMB}$ at $100 \mathrm{ul} /$ well, and then incubated for $15-30 \mathrm{~min}$ at $37^{\circ} \mathrm{C}$. Finally, stop solution $\left(2 \mathrm{M} \mathrm{H}_{2} \mathrm{SO}_{4}\right)$ was added into the plates at 50 $\mu \mathrm{l} /$ well.

The OD value of each well was measured at a single wavelength of $450 \mathrm{~nm}$, and the ratio (Positive/Ngetive, $\mathrm{P} / \mathrm{N}$ ) of the $\mathrm{OD}$ value to the negative control well was greater than 2.1 as a critical point judged to be positive or negtive.

96 well plates were added with $150 \mu \mathrm{l} 0.1 \mathrm{M} \mathrm{NaHCO} 3$ plus $2.5 \%$ glutaraldehyde, incubated for $1 \mathrm{~h}$ at 37 ${ }^{\circ} \mathrm{C}$, and washed four times with sterile water. The plates were then coated with $10^{7} \mathrm{CFU} / 100 \mu \mathrm{l} R A$ cells per well and incubated at $37^{\circ} \mathrm{C}$ until dry. Subsequent steps from antigen blocking were carried out in accordance with the above iELISA procedure.

\section{Serum bactericidal assay (SBA)}

The serum 7 days after the second immunization was used for SBA. A single colony of the purely cultured strain was picked, inoculated into TSB medium, and cultured to the early stage of growth (OD $600=1.5$ or so). After washing with PBS, it was diluted to $10^{8} \mathrm{cfu} / \mathrm{ml}$.Duck serum was diluted to a range of concentrations of $100 \%, 50 \%, 25 \%, 12.5 \%, 5 \%$ with PBS. Inactivated $100 \%$ duck serum and PBS were used as controls. $10 \mathrm{uL}$ of the prepared bacterial solution was mixed with $190 \mathrm{uL}$ of different concentrations of duck serum and incubated at $37^{\circ} \mathrm{C}$ for $30 \mathrm{~min}$. The number of bacteria survived was counted by plate counting. 
The serum 7 days after the second immunization was used for Opsonophagocytosis assay. $R A$ single colonies were picked, inoculated into TSB liquid medium, and cultured to the early stage of growth (OD $600=1.5$ or so). After washing with PBS, it was diluted to $5 \times 10^{4} \mathrm{CFU} / \mathrm{ml} .20 \mu \mathrm{l}$ of the test serum was added to the 96 -well cell plate and incubate for $20 \mathrm{~min}$ at $37^{\circ} \mathrm{C} .10 \mu \mathrm{l}$ of duck complement and $40 \mu \mathrm{l}$ of duck blood was add into the plates and incubate for 1 hour at $37^{\circ} \mathrm{C}$ with shaking. The number of bacteria survived was counted by plate counting.

\section{Challenge assay}

30 one-day-old cherry valley ducks were randomly divided into three groups. Porin protein with adjuvant, PBS with adjuvant and PBS were separately immunized according to the previous method. After 14 days of secondary immunization, 10 times and a half lethal dose (LD50) $R A C H 1$ was intraperitoneally injected for 1 week, and survival rate after challenge was recorded.

\section{Statistical analysis}

The SigmaPlot software (version 12) and graphpad prism 8.0.2 were used for all statistical analyses. One-way repeated analysis of variance (ANOVA) and the Mann-Whitney rank test were used to evaluate differences between groups. Differences were considered significant at $\mathrm{p}<0.05$.

\section{Results}

\section{Signal peptide prediction}

Cleavage site of Porin protein was between pos. 18 and 19: LKS-QE, and probability of prediction was 0.6038 .

\section{Homology Analysis}

The top 50 sequences with the highest similarity to the Porin protein in the Uniprot database were extracted for comparison. The identity of Porin protein in $R A$ was above $94.2 \%$, blew $68 \%$ with other strains. The evolutionary history was inferred by using the Maximum Likelihood method based on the JTT matrix-based model(Jones, Taylor, \& Thornton, 1992). The result was shown in Fig. 1. The tree with the highest log likelihood (-11905.39) is shown. The analysis involved 50 amino acid sequences. There were a total of 451 positions in the final dataset. Evolutionary analyses were conducted in MEGA X(Kumar, Stecher, Li, Knyaz, \& Tamura, 2018). The Porin protein was conservative in RA.

\section{Discussion}

RA mainly infects ducks, geese and turkeys, et al, and young animals have a higher mortality rate after infection. Antibiotic treatment has led to increasing resistance to $R A$. The current vaccines against $R A$ are 
mainly inactivated vaccines(Liu et al.) and subunit vaccines(Chu, Liu, Liou, Lee, \& Cheng, 2015). However, there are many $R A$ serotypes, and the cross-immunoprotective effect between each serotype is weak. Currently reported serotypes with cross-immunoprotection are serotypes 1 and 2(Zhai et al., 2013). So, it is particularly important to develop subunit vaccines that have immune protection against multiple serotypes of $R A$.

The Porin protein has been reported to be immunoprotective in other strains. However, the protein was only presumed to be present in $R A$ by sequencing, and has not been analyzed by recombinant expression, nor has it been verified whether it has immune protection against $R A$. The protein was firstly analyzed using bioinformatics tools. By blast comparison and Phylogenetic tree analysis, it can be seen that the protein is highly conserved in $R A$ and has low similarity to Proin protein of other strains. It could be speculated that if the protein has immunoprotective effect on serotype $1 R A$, then it may also have immunoprotective effect on other serotype $R A$. Our previous research also showed that even if the conserved antigen exists in different bacterial species, the antigen will provide cross-immunity protection(Guan et al., 2015; Guan, Wang, Wang, Teng, \& Wang, 2016). The transmembrane structure and epitope of Porin protein in $R A$ were also predicted. Only epitopes located outside the membrane have the potential to develop vaccines. After screening, 9 linear epitopes and 2 spatial epitopes were considered to be effective. According to the analysis, this protein is conserved in $R A$ and has abundant epitopes, which may have the potential to develop vaccines.

Bioinformatics analysis also showed that the protein may be expressed as inclusion bodies in E. coli. Therefore, the expressed protein needs to be refolded and renatured. The membrane protein contains a transmembrane portion and a hydrophilic portion. In order to keep the protein as natural as possible, a mild detergent needs to be added to the refolding buffer.

Serum antibody affinity was analyzed by iELISA. 28 days after the initial immunization, duck serum antibodies still have a strong affinity for Porin protein and serotype $1 R A$ strains. SBA and opsonization phagocytosis also prove that serum antibodies can improve the elimination of $R A$ by the immune system. Compared with the control group, the survival rate of Porin protein immunized group after challenge increased, indicating that the protein has the potential to be developed into a vaccine.

\section{Declarations}

The article is original, has been written by the stated authors who are all aware of its content and approve its submission, and has not been published previously. It is not under consideration for publication elsewhere, no conflict of interest exists. If accepted, the article will not be published elsewhere in the same form, in any language, without the written consent of the publisher.

\section{Declarations}

The article is original, has been written by the stated authors who are all aware of its content and approve its submission, and has not been published previously. It is not under consideration for publication 
elsewhere, no conflict of interest exists. If accepted, the article will not be published elsewhere in the same form, in any language, without the written consent of the publisher.

\section{Ethics approval and consent to participate}

The experimental protocol was established, according to the ethical guidelines of Hainan University Institutional Animal Use and Care Committee and was approved by the international bioethics committee. Written informed consent was obtained from individual or guardian participants.

\section{Consent for publication}

Not applicable.

\section{Availability of data and material}

All data generated or analysed during this study are included in this published article.

\section{Competing interests}

The authors declare that they have no competing interests.

\section{Funding}

This study was supported by Hainan Provincial Natural Science Foundation of China (317030) and Hainan Science and Technology Project (ZDYF2018085).

\section{Authors' contributions}

QG and QH conceived and designed research. HY and $\mathrm{HZ}$ conducted experiments. KW contributed new reagents or analytical tools. CL, JZ and JW analyzed data. QG wrote the manuscript. All authors read and approved the manuscript.

Acknowledgements

This study was supported by Hainan Science and Technology Project (ZDYF2018085),Hainan Provincial Natural Science Foundation of China (317030).

\section{References}

1. Bagos PG, Liakopoulos TD, Spyropoulos IC, Hamodrakas SJ (2004) PRED-TMBB: a web server for predicting the topology of beta-barrel outer membrane proteins. Nucleic Acids Res, 32(Web Server issue), W400-W404. doi:10.1093/nar/gkh417

2. Bahey-El-Din M, Mohamed SA, Sheweita SA, Haroun M, Zaghloul TI (2020) Recombinant N-terminal outer membrane porin (OprF) of Pseudomonas aeruginosa is a promising vaccine candidate against 
both P. aeruginosa and some strains of Acinetobacter baumannii. Int J Med Microbiol 310(3):151415. doi:10.1016/j.ijmm.2020.151415

3. Chen YP, Lee S-H, Chou C-H, Tsai H-J. Detection of florfenicol resistance genes in Riemerella anatipestifer isolated from ducks and geese. 154(3-4), 325-331

4. Chu CY, Liu CH, Liou JJ, Lee JW, Cheng LT (2015) Development of a subunit vaccine containing recombinant Riemerella anatipestifer outer membrane protein A and CpG ODN adjuvant. Vaccine 33(1):92-99

5. Dodd CC, Renter DG, Thomson DU, Nagaraja TG (2011) Evaluation of the effects of a commercially available Salmonella Newport siderophore receptor and porin protein vaccine on fecal shedding of Salmonella bacteria and health and performance of feedlot cattle. Am J Vet Res 72(2):239-247. doi:10.2460/ajvr.72.2.239

6. Fox JT, Thomson DU, Drouillard JS, Thornton AB, Nagaraja TG (2009) Efficacy of Escherichia coli 0157:H7 Siderophore Receptor/Porin Proteins-Based Vaccine in Feedlot Cattle Naturally Shedding E. coli 0157. Foodborne Pathogens \& Disease, 6(7), 893-899

7. Guan Q, Wang X, Wang X, Teng D, Mao R, Zhang Y, Wang J (2015) Recombinant outer membrane protein $\mathrm{A}$ induces a protective immune response against Escherichia coli infection in mice. Appl Microbiol Biotechnol 99(13):5451-5460. doi:10.1007/s00253-014-6339-6

8. Guan Q, Wang X, Wang X, Teng D, Wang J (2016) In silico analysis and recombinant expression of BamA protein as a subunit vaccine against Escherichia coli in mice. Appl Microbiol Biotechnol 100(11):5089-5098. doi:10.1007/s00253-016-7467-y

9. Hinz KH, Ryll M, Köhler B (1998) Detection of acid production from carbohydrates by Riemerella anatipestifer and related organisms using the buffered single substrate test. 60(2-4), 277-284

10. Jones DT, Taylor WR, Thornton JM (1992) The rapid generation of mutation data matrices from protein sequences. Comput Appl Biosci, 8(3), 275-282. Retrieved from https://www.ncbi.nlm.nih.gov/pubmed/1633570

11. Kumar S, Stecher G, Li M, Knyaz C, Tamura K (2018) MEGA X: Molecular Evolutionary Genetics Analysis across Computing Platforms. Mol Biol Evol 35(6):1547-1549.

doi:10.1093/molbev/msy096

12. Liu H, Wang X, Ding C, Han X, Cheng A, Wang S, Yu S Development and Evaluation of a Trivalent Riemerella anatipestifer-Inactivated Vaccine. Clinical \& Vaccine Immunology Cvi, 20(5), 691-697

13. Rubbenstroth D, Ryll M, Behr KP, Rautenschlein S Pathogenesis of Riemerella anatipestifer in turkeys after experimental mono-infection via respiratory routes or dual infection together with the avian metapneumovirus. Avian Pathology, 38(6), p. 497-507

14. Saleem M, Moore J, Derrick JP J. M. i. M. B. (2012). Expression, Purification, and Crystallization of Neisserial Outer Membrane Proteins. 799, 91-106

15. Shu-Chuan W, Wen-Hua L, Yung-Fu C, Chao-Fu C (1999) Identification of a virulence-associated protein homolog gene and ISRa 1 in a plasmid of Riemerella anatipestifer. Fems Microbiology Letters(1), 1 
16. Studier FW (2014) Stable Expression Clones and Auto-Induction for Protein Production in E. coli. $1091,17-32$

17. Sun J, Zhu D, Xu J, Jia R, Cheng A (2019) Rifampin resistance and its fitness cost in Riemerella anatipestifer. Bmc Microbiology, 19(1)

18. Xing L, Yu H, Qi J, Jiang P, Sun B, Cui J,.. . Hu Q (2015) ErmF and ereD Are Responsible for Erythromycin Resistance in Riemerella anatipestifer. Plos One 10(6):e0131078

19. Zhai Z, Li X, Xiao X, Yu J, Chen M, Yu Y, Zhang W (2013) Immunoproteomics selection of crossprotective vaccine candidates from Riemerella anatipestifer serotypes 1 and 2. Vet Microbiol 162(24):850-857. doi:10.1016/j.vetmic.2012.11.002

20. Zhu TF, Chen FF, Li JC (2017) A strain of pathogenic Bacillus subtilis results in brain damage in ducklings when co-infected with Riemerella anatipestifer. 20(4), 803

\section{Tables}

Table 1 linear epitopes outside of outer membrane in $R A$.

\begin{tabular}{|lllll|}
\hline No. & Start & End & Peptide & Number of residues \\
\hline 1 & 52 & 67 & YYNFGKGVGITSPDSLF & 16 \\
\hline 2 & 86 & 94 & NRSTEYKAA & 9 \\
\hline 3 & 125 & 133 & GEIKEGNPL & 9 \\
\hline 4 & 196 & 202 & NNTKANE & 7 \\
\hline 5 & 235 & 246 & YPLGAFKNNGEF & 12 \\
\hline 6 & 278 & 287 & RGKELLESRD & 10 \\
\hline 7 & 314 & 329 & SNPLTHNTDFSKVIPV & 16 \\
\hline 8 & 359 & 368 & NKSIQNLIPK & 10 \\
\hline 9 & 392 & 406 & SKNNFLYIDGRKDNN & 15 \\
\hline
\end{tabular}

Table 2 spatial epitopes outside of outer membrane in $R A$ 


\begin{tabular}{|lll|}
\hline No. & Residues & $\begin{array}{c}\text { Number } \\
\text { of } \\
\text { residues }\end{array}$ \\
\hline 1 & A:S271, A:N272, A:F273, A:Q275, A:G276, A:G279, A:K280, A:E281, A:L282, A:L283, & 41 \\
& A:E284, A:S285, A:R286, A:D287, A:S314, A:N315, A:P316, A:L317, A:T318, A:H319, & \\
& A:N320, A:T321, A:D322, A:F323, A:S324, A:K325, A:V326, A:I327, A:P328, A:V329, \\
& A:K360, A:S361, A:I362, A:Q363, A:N364, A:L365, A:I366, A:P367, A:K368, A:L397, & \\
& A:Y398 & \\
\hline 2 & A:N77, A:L79, A:E80, A:A81, A:D82, A:F83, A:N84, A:D85, A:N86, A:S88, A:T89, A:E90, & 38 \\
& A:Y91, A:K92, A:A93, A:A94, A:P236, A:L237, A:G238, A:A239, A:F240, A:K241, & \\
& A:N242, A:N243, A:G244, A:E245, A:F246, A:K393, A:N395, A:F396, A:I399, A:D400, & \\
& A:G401, A:R402, A:K403, A:D404, A:N405, A:N406 & \\
\hline
\end{tabular}

\section{Figures}



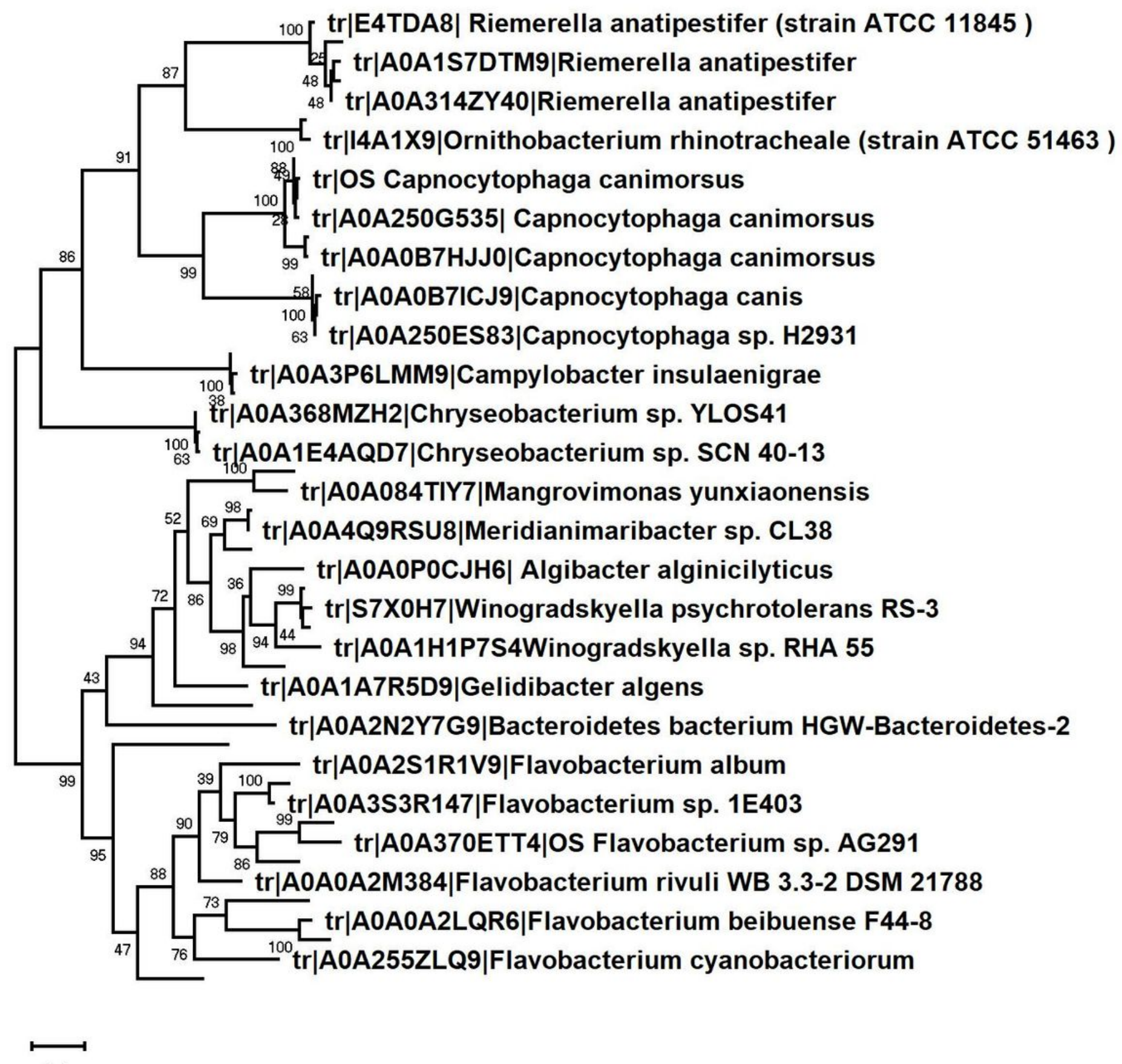

0.1

Figure 1

Molecular Phylogenetic analysis by Maximum Likelihood method 


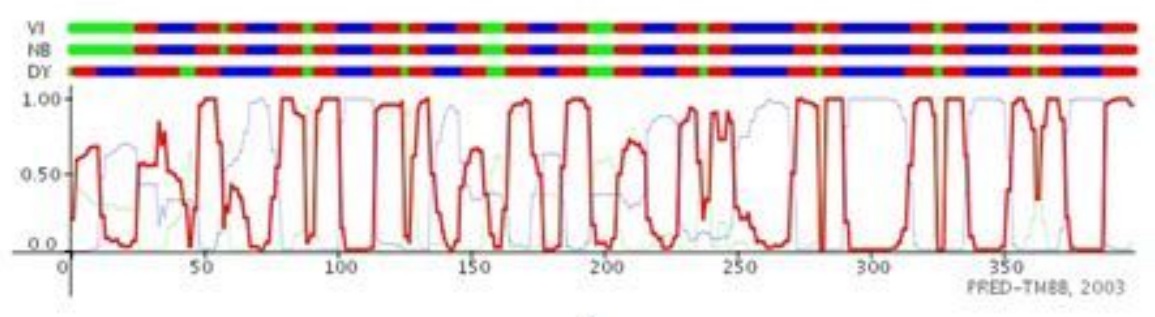

A

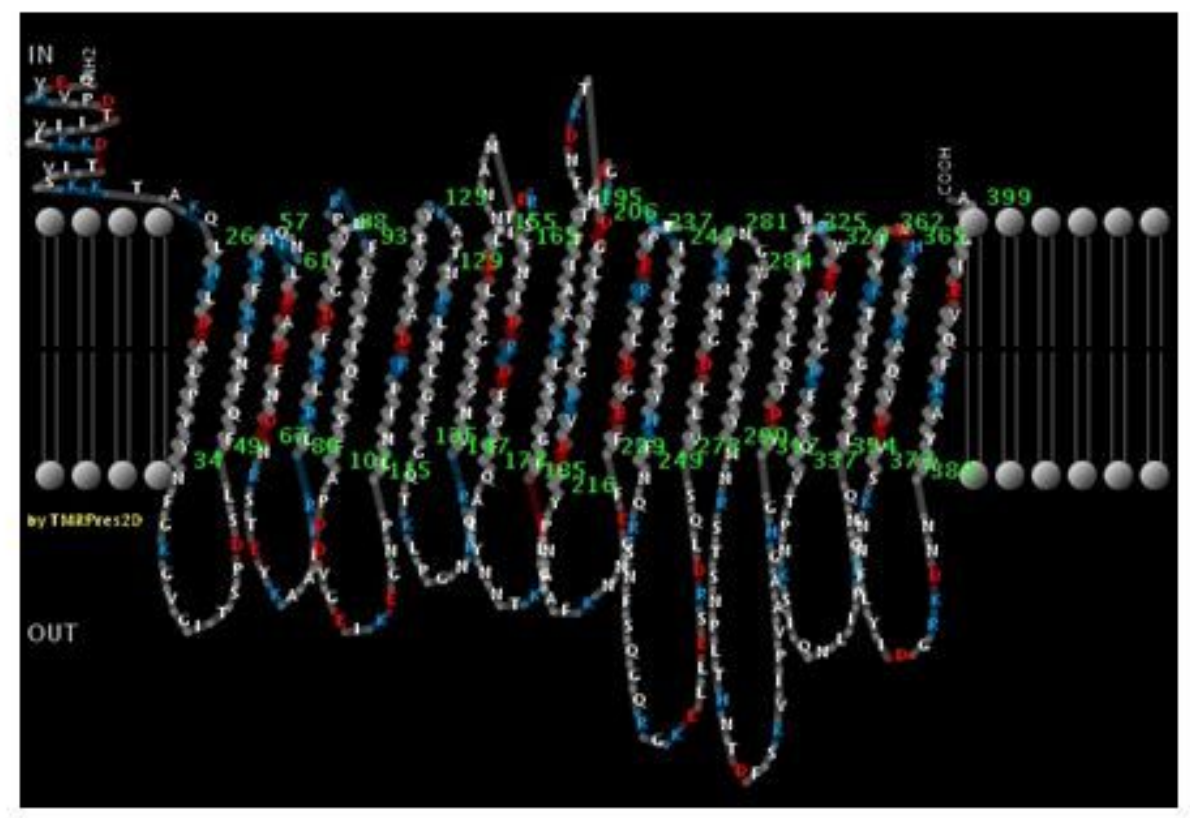

\section{Figure 2}

Transmembrane structure prediction of Porin protein. A: Prediction by VI, NB and DY methods. B: common elements of the prediction in three methods.

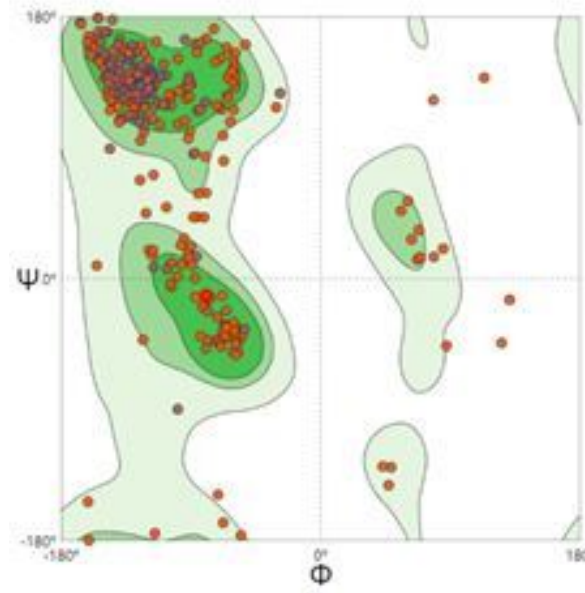

A

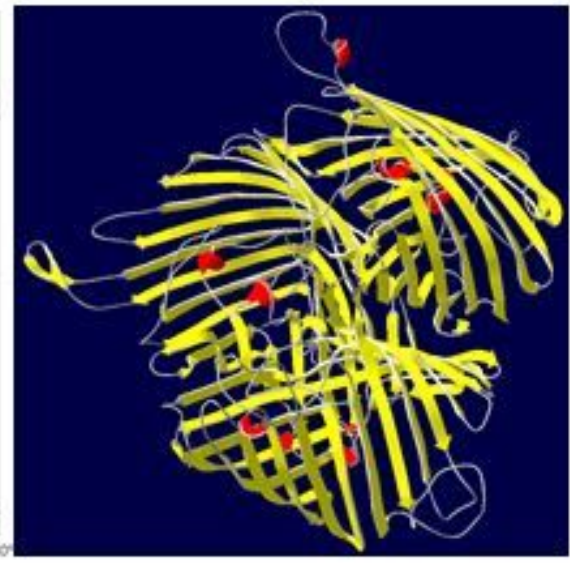

B

\section{Figure 3}

Tertiary structure prediction of Proin protein. A: Structure assessment of the model by Ramachandran Plots. B: 3D structure of PorinM. 


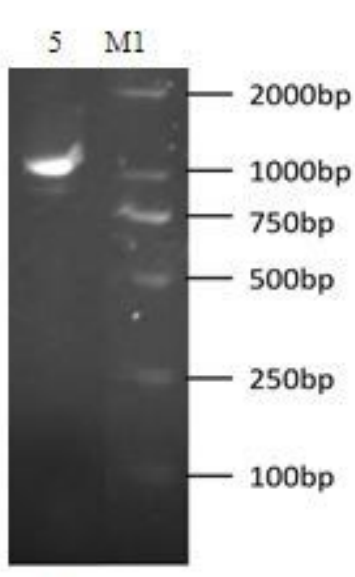

A

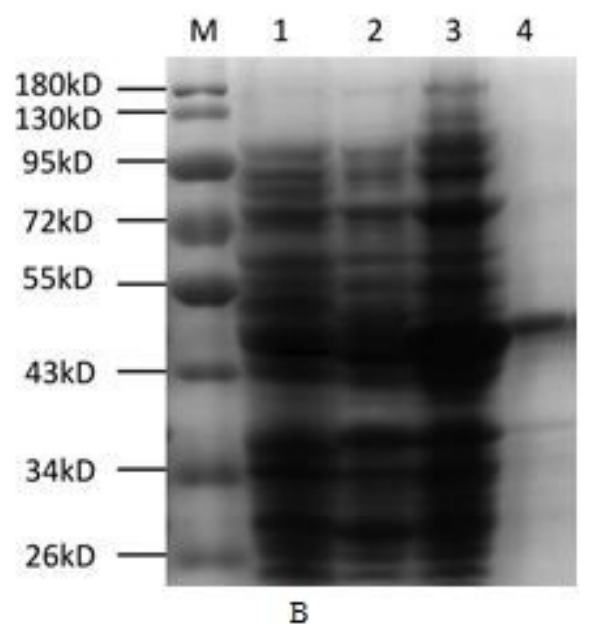

\section{Figure 4}

Electrophoresis of Porin gene cloning and protein purification. 4A: Agarose gel electrophoresis of Porin gene. 4B:SDS-PAGE of Porin protein. M: 180 kd protein ruler. M1: Trans 2K DNA marker. 1: BL21 strain. 2: BL21 strain with pET 28a vector. 3: BL21 strain with Porin gene. 4: Purified Porin. 5: Porin gene.

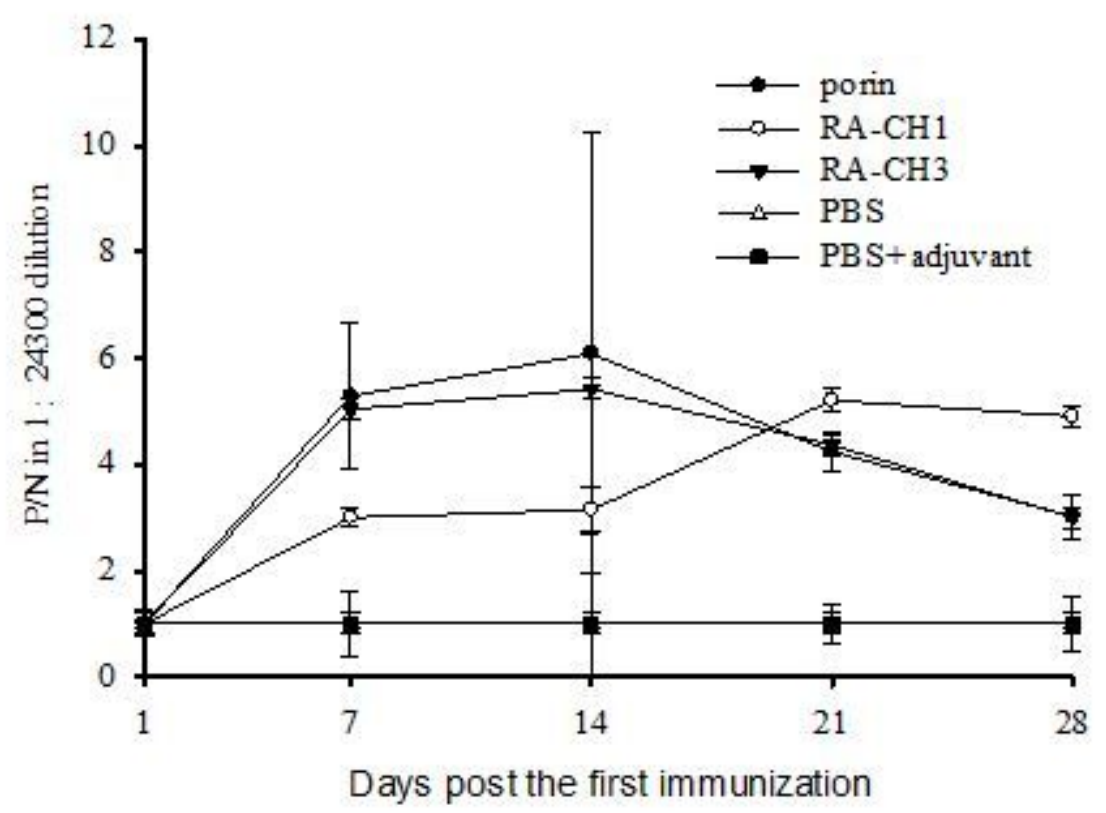

Figure 5

IELISA for Porin immunization serum. 


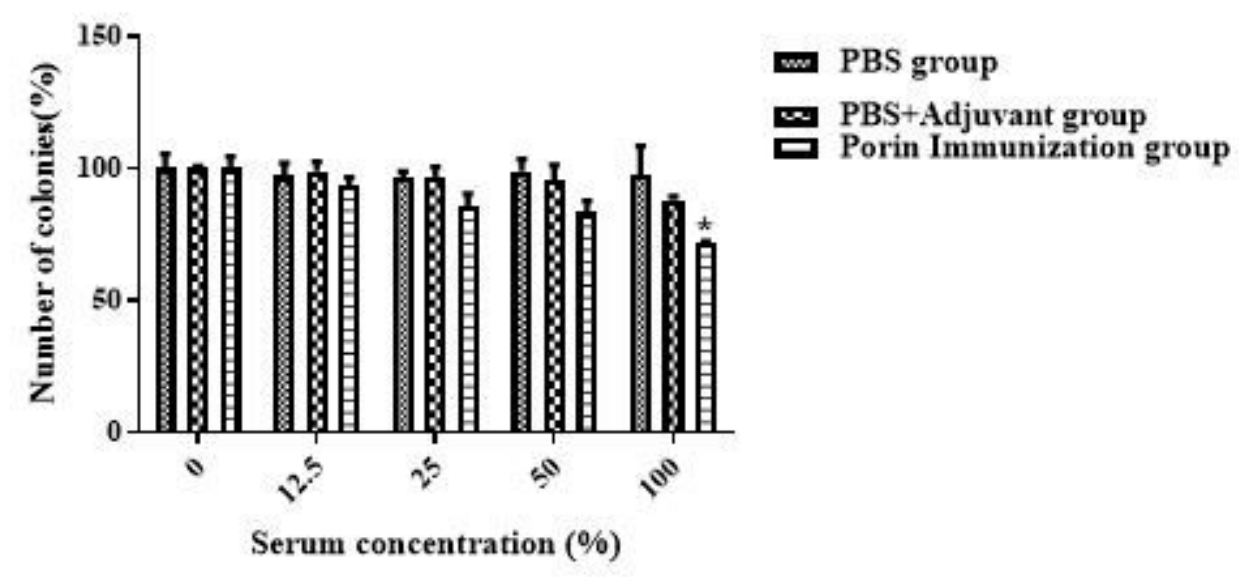

Figure 6

Colonies change in different dilution of surum.

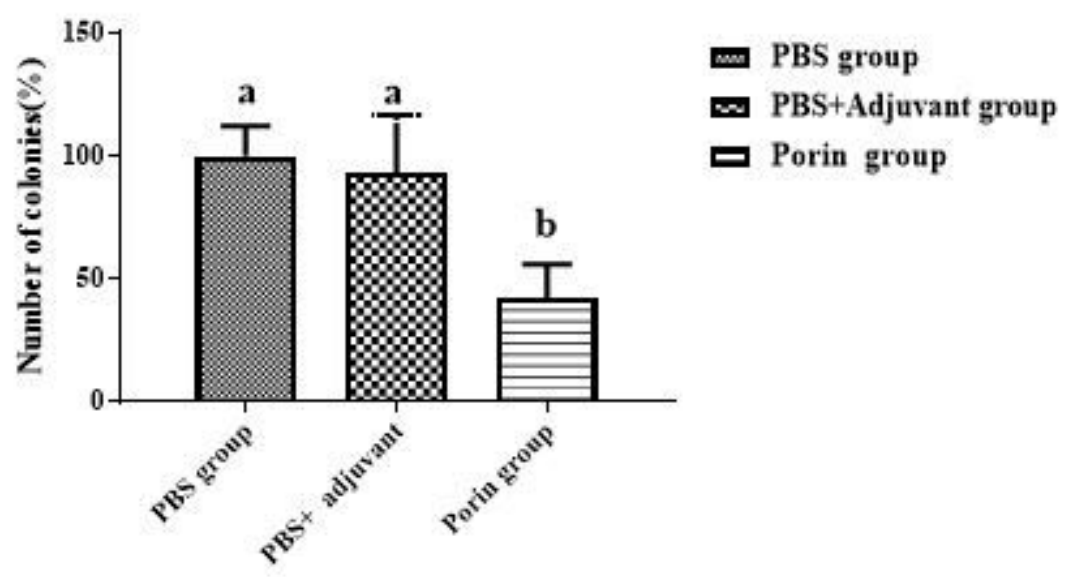

Figure 7

Phagocytosis of the rBamA sera in vitro. 


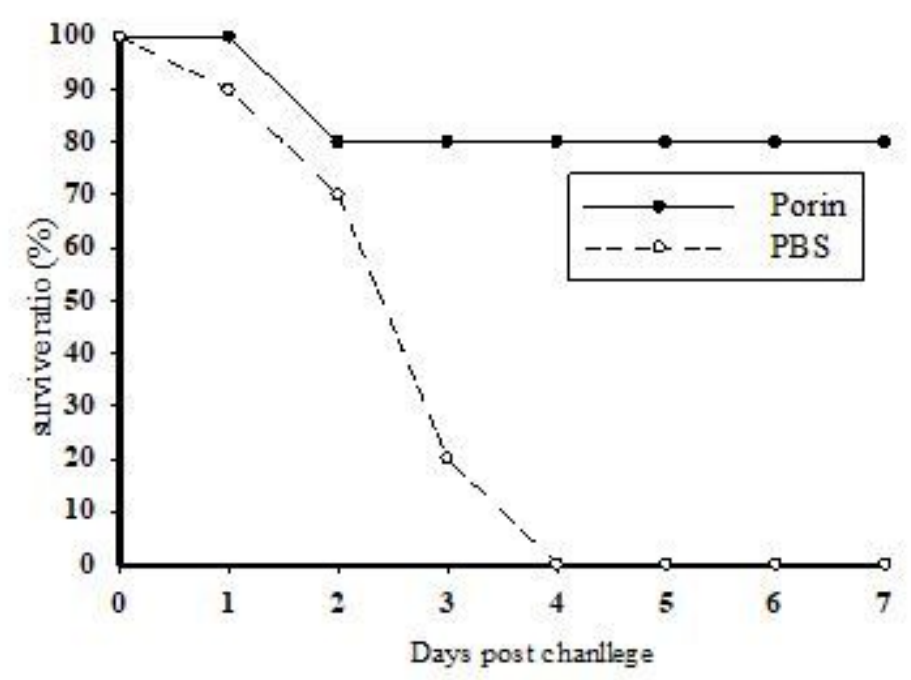

Figure 8

Survival percent of the mice immunized with Porin or PBS. 